\title{
A Privacidade e a Proteção dos Dados Pessoais no Ciberespaço como um Direito Fundamental: perspectivas de construção de um marco regulatório ${ }^{1}$ para 0 Brasil $^{2}$
}

\section{Privacy and Personal Data Protection in Cyberspace as a Fundamental Right: prospects for a regulatory framework for Brazil}

\section{Salete Oro Boff}

IMED - Faculdade Meridional, Passo Fundo, RS, Brasil UNISC - Universidade de Santa Cruz do Sul, RS, Brasil

Vinícius Borges Fortes

IMED - Faculdade Meridional, Passo Fundo, RS, Brasil

\begin{abstract}
Resumo: A evolução tecnológica na área da comunicação e da informação no ciberespaço oferece novas e diferentes possibilidades de futuro, mas pode representar uma afronta aos direitos fundamentais da privacidade e da proteção aos dados pessoais. A partir dessa constatação, serão analisadas as perspectivas brasileiras da instituição de marcos regulatórios para a governança do ciberespaço, com o fim de indicar o modo e em que medida tais instrumentos normativos são capazes de assegurar a proteção jurídica do direito à privacidade e à inviolabilidade dos dados pessoais. O método utilizado é o dialético e o monográfico e a técnica de pesquisa bibliográfica.
\end{abstract}

Palavras-chave: Privacidade e Proteção de Dados. Ciberespaço. Marco Regulatório.

\begin{abstract}
Technological developments in the area of communication and information in cyberspace, offers new and different possibilities for the future, but may represent an affront to the fundamental rights of privacy and protection of personal data. From this observation, analyzes the prospects Brazilian institution regulatory frameworks for the governance of cyberspace, in order to indicate how and to what extent such regulatory instruments are able to ensure the legal protection of the right to privacy and inviolability of personal data. The method used is the dialectical and monographic literature and technique.
\end{abstract}

Keywords: Privacy and Data Protection. Cyberspace. Regulatory Framework.

\footnotetext{
1 A pesquisa foi desenvolvida com base no Projeto de Lei n. ${ }^{\circ}$ 2.126/2011. Após o aceite deste trabalho para publicação, o referido Projeto de Lei foi aprovado pela Câmara dos Deputados (25 de março de 2014), com aprovação confirmada pelo Senado Federal (22 de abril de 2014), com sanção da Presidenta da República em 23 de abril de 2014 e publicação no Diário Oficial da União em 24 de abril de 2014 como Lei n. ${ }^{\circ}$ 12.965/2014, que instituiu no Brasil o Marco Civil da Internet.
}

\footnotetext{
2 Recebido em: 13/08/2013
}

Revisado em: 30/09/2003

Aprovado em: 30/03/2014 


\section{Introdução}

O progresso da humanidade se reflete na capacidade de transmitir informações. As questões de tempo e distância, na área da informação, têm sua amplitude reduzida. O direito à informação expandiu-se, facilitando o acesso ao conhecimento nos mais diversos pontos do planeta. Colabora expressivamente a internet neste campo. O espaço virtual (ciberespaço) é um espaço social, formado pelo fluxo de informações e de mensagens transmitidas entre computadores. É uma rede aberta, qualquer pessoa pode ter acesso a ela. Possui caráter interativo possibilitando ao usuário gerar dados, navegar e estabelecer relações na rede. Por meio de provedores de acesso se realizam várias atividades como o correio eletrônico; a computação de longa distância, o comércio eletrônico, o lazer, a pesquisa e outros. A World Wide Web (teia de alcance mundial) é a tecnologia utilizada para acessar a internet.

Indistintamente, pela internet todos podem se comunicar, para tanto, basta possuir um computador, um modem e uma linha telefônica. Ampliou-se a facilidade de acesso à informação armazenada em computadores, quer se trate de informações livremente disponíveis, quer se trate de informações e dados pessoais de ordem privada.

Nesse contexto de inegável evolução das tecnologias, o avanço da internet e a constituição do ciberespaço carecem de uma análise jurídica, normativa, sociológica, cultural e até mesmo psicológica. Com a evolução dos recursos da internet, é oportuna a reflexão quanto aos insumos contributivos à cultura, acesso e democratização da informação, valorização da diversidade e o processo de inclusão digital.

Contudo, também é indispensável refletir sobre os problemas jurídicos decorrentes da massificação do uso da internet. Assim, o estudo crítico no entorno do tema dos direitos humanos fundamentais à privacidade e à proteção aos dados pessoais é relevante para o meio jurídico, sobretudo quando se trata de uma reflexão frente aos marcos regulatórios do ciberespaço, que vão de encontro às premissas de criação da internet, que pressupõem a não regulação. 
No Brasil é possível observar estudos que se ocupam dos reflexos da internet sobre os institutos de direito do consumidor e da necessidade de regulação da internet em matéria penal, para fins de tratamento adequado aos denominados cibercrimes. Sem desmerecer as mencionadas abordagens, no Brasil há escassez de estudos voltados para a análise do direito à privacidade e à proteção dos dados em um contexto denominado como a era do culto do amador e do culto do social, em que os próprios usuários são induzidos, ou seduzidos, ao exibicionismo exacerbado, com a renúncia do direito humano fundamental da privacidade e com o fornecimento de dados pessoais tão valiosos que compensam a oferta de serviços na internet de forma gratuita.

Nesse sentido, o confronto entre a evolução tecnológica, o direito e os marcos regulatórios para o ciberespaço é inevitável para uma melhor compreensão da sociedade da informação, ou da sociedade em rede. Assim, a pesquisa se propõe a analisar as perspectivas brasileiras no contexto global e a real necessidade da instituição de marcos regulatórios para a governança do ciberespaço, e, de forma específica, verificar o modo e em que medida tais instrumentos normativos são capazes de assegurar a proteção jurídica do direito à privacidade e à inviolabilidade dos dados pessoais.

Com essas considerações, pretende-se buscar resposta para a seguinte indagação: é possível instituir marcos regulatórios para a governança do ciberespaço no Brasil como um modo de assegurar a proteção jurídica do direito à privacidade e à inviolabilidade dos dados pessoais?

Considerando o objeto de pesquisa proposto, que se alinha a uma postura construtivista para desvelamento do problema, formula-se a seguinte hipótese principal: o Brasil poderá seguir as diretrizes globais de governança do ciberespaço que orientam a construção de marcos regulatórios locais e que atendam às particularidades culturais e sociológicas dos Estados.

Para tanto, é indispensável entender que a construção de um modelo normativo de governança do ciberespaço deverá respeitar as premissas de construção da Web, sem que ocorram rupturas paradigmáticas com a 
arquitetura adotada com a sua constituição e com a constante adaptação que culminou na constituição da cibercultura e do ciberespaço.

Esta pesquisa desenvolve o método de análise do mapeamento crítico, verificando as possibilidades de instituição de marcos regulatórios para a governança do ciberespaço no Brasil que tenham por escopo assegurar a proteção jurídica do direito humano à privacidade e à inviolabilidade dos dados pessoais.

A pesquisa tem como objetivos: (i) observar e mapear as diferentes propostas de governança do ciberespaço no contexto brasileiro; (ii) analisar nas diferentes propostas os instrumentos sugeridos para assegurar a proteção jurídica do direito humano fundamental à privacidade e à inviolabilidade dos dados pessoais no Brasil; (iii) contextualizar a relação do ciberespaço e da cibercultura sobre os fenômenos históricos, culturais, sociais e jurídicos recentes; (iv) delimitar as dimensões de violações ao direito à privacidade e à proteção de dados para o desenvolvimento do método do mapeamento e crítica sobre as observações e análises.

Contudo, o que se evidencia no contexto brasileiro é que, com a evolução das tecnologias que contribuem para o avanço do ciberespaço, ainda não se conferiu a devida relevância à análise jurídica, normativa, sociológica, cultural e até mesmo psicológica, quanto à viabilidade e à necessidade da instituição de marcos regulatórios para a governança do ciberespaço de modo a assegurar a proteção jurídica do direito fundamental à privacidade e à inviolabilidade dos dados pessoais, buscando a construção de um modelo normativo de governança do ciberespaço que respeite as premissas de construção da Web sem que ocorram rupturas paradigmáticas com a arquitetura adotada com a sua constituição e constante adaptação que culminou na constituição da cibercultura e do ciberespaço.

\section{O Que é Isto - O Ciberespaço?}

A pesquisa tem diversas variáveis de natureza epistemológica, que perpassam necessariamente pela relativização da teoria do direito em virtude de um novo contexto global e social com o avanço da tecnologia da 
informação e comunicação. De acordo com o professor da Stanford University, Lessig (2006, p. 3-5), o conceito de ciberespaço varia rapidamente, sobretudo em razão da identidade evidenciada no tempo e no espaço de acordo com os objetivos de uso da rede pelos usuários.

Para exemplificar tal afirmação, o referido professor utiliza como exemplo o discurso intitulado "Declaração de Independência para o Ciberespaço" proclamado logo após o rompimento da cultura bipolar com o fim da Guerra Fria pelo compositor do Grateful Dead, banda de Rock dos anos de 1960, John Perry Barlow, que também é fundador da Eletronic Frontier Foundation (EFF), uma organização não governamental que tem como escopo a defesa dos interesses dos usuários da Web, no qual pronuncia: "Governos da Era Industrial, vocês gigantes aborrecidos de carne e aço, eu venho do ciberespaço, o novo lar da Mente. Em nome do futuro, eu peço a vocês do passado que nos deixem em paz. Vocês não são bem-vindos entre nós. Vocês não tem soberania onde nos reunimos".

A partir disso, é possível identificar uma constante mudança sobre a percepção do ciberespaço e das possibilidades de regulação e governança, sobretudo no que diz respeito ao alcance de instrumentos normativos que assegurem a proteção jurídica do direito à privacidade e à inviolabilidade dos dados pessoais.

Assim, o confronto entre a evolução tecnológica, o direito e os marcos regulatórios para o ciberespaço, em especial no contexto brasileiro, torna-se inevitável para uma melhor compreensão da sociedade da informação, ou da sociedade em rede, como refere Castells (2002).

\section{Perspectivas da Privacidade e Organização Social no Ciberes- paço}

To the future or to the past, to a time when thought is free, when men are different from one another and do not live alone - to a time when truth exists and what is done cannot be undone: From the age of uniformity, from the age of solitude, from the age of Big Brother, from the age of doublethink - greetings! 
A partir da reflexão proposta por Orwell, na obra 1984, com a era do "Grande Irmão" e o "Ministério da Verdade", e a desintegração do conceito de privacidade e de intimidade, é relevante refletir sobre o tema no contexto em que a evolução das tecnologias da informação e comunicação oportunizam uma experiência de interação entre os usuários da internet em patamares jamais imaginados.

Isso porque, como se sabe, a internet trilhou seus primeiros passos em 1969, a partir da criação do The Advanced Research Projects Agency Network (ARPNET), com a finalidade de atender demandas do Departamento de Defesa dos Estados Unidos da América, sobretudo em virtude das incertezas bélicas da Guerra Fria. A partir disso, as conexões em rede cresceram significativamente, até a criação no final da década de 1980 da World Wide Web (www), pelo físico Tim Berners-Lee e, no início da década de 1990, o desenvolvimento dos primeiros softwares para navegação em páginas da internet. (VASCONCELOS, 2003. p. 34)

Com a evolução da tecnologia e dos recursos vinculados à rede mundial de computadores, a World Wide Web, ou internet como ficou popularizada, ficou conveniente a reflexão sobre os insumos contributivos à cultura, ao acesso e à democratização da informação, da valorização da diversidade e do processo de inclusão digital. Contudo, também é indispensável promover reflexões voltadas aos problemas jurídicos advindos da evolução tecnológica, principalmente os decorrentes da massificação do uso da internet.

Nessa órbita, promover o estudo crítico no entorno do tema do direito à privacidade e à proteção aos dados pessoais é de significativa importância para o meio jurídico, sobretudo quando se trata de uma reflexão sobre os marcos regulatórios instituídos em escala global, com o objetivo de normatizar o ciberespaço, indo de encontro com as premissas de criação da internet, que pressupunham a não regulação.

Ademais, é possível observar diversos estudos que se ocupam da abordagem dos reflexos da rede sobre os institutos de direito do consumidor e, nos últimos anos, da (des) necessidade de regulação da internet em matéria penal, para fins de tratamento (in) adequado aos denominados cibercrimes. 
Contudo, sem desmerecer as mencionadas abordagens, há escassez de estudos voltados à análise do direito à privacidade e à proteção dos dados num contexto em que Keen denomina como a era do culto do amador (KEEN, 2009) e do culto do social (KEEN, 2012), em que os próprios usuários são induzidos, ou seduzidos, ao exibicionismo exacerbado, com a renúncia da privacidade e com o fornecimento de dados pessoais tão valiosos, que compensam a oferta de serviços de forma gratuita, como o fazem as grandes corporações do Vale do Silício, Google e Facebook.

Até tal etapa da história da internet, jamais se imaginou que grandes corporações do Vale do Silício revolucionariam a experiência de interatividade entre usuários. Nesse aspecto, Keen (2009) alerta para a interação proporcionada pela Web 2.0, que se caracteriza pela utilização de plataformas informacionais como os blogs, o Wikipedia, o YouTube e o MySpace, como formas de propagação de conteúdo que constituem o que o autor denomina como o "culto do amador". De acordo com o pensador, tais plataformas passaram a comprometer a economia, a cultura e os valores da sociedade, pela baixa confiabilidade, pela banalização e, por óbvio, pelo amadorismo dos conteúdos postados na rede.

A geração tecnológica atual vivencia a experiência da Web 3.0, constituída pelas redes sociais como o Facebook, Google+ e Twitter, por exemplo, amplamente criticadas por Keen (2012) por caracterizar-se essencialmente pelo "culto do social" ou a "era do grande exibicionismo". Para o autor, a Web 3.0 desafia a lei tradicional que protege os indivíduos, como exemplo, é possível mencionar o caso Ryan Giggs, que provocou cerca de 75 mil usuários do Twitter a compartilhar detalhes das relações extraconjugais do jogador de futebol, ainda que na vigência de uma determinação da Suprema Corte britânica que vedava comentários públicos sobre a vida privada do atleta.

Para Keen (2012), o fenômeno envolvendo a reputação de Giggs resulta no que Barber (2013), editor do Financial Times descreve como o "debate sobre a liberdade de nossa era". De acordo com Barber (2013), de um lado a lei não dispõe de poder suficiente para punir simultaneamente 75 mil usuários de internet por "tuitar" sobre a vida sexual de uma pessoa pública; contudo, em sentido antagônico, a lei que assegura proteção aos 
direitos individuais perante a sociedade deveria possibilitar uma espécie de imunidade contra a "ridicularização pública" num momento da história da humanidade intitulado "era digital", em que qualquer indivíduo se sente no direito, e muitas vezes no dever, de publicar ou compartilhar qualquer coisa sobre outro indivíduo.

Não bastassem os acontecimentos envolvendo a violação de privacidade e a publicação deliberada desses dados, a atual geração tecnológica tem como grande elemento catalizador das empresas de tecnologia da informação e comunicação a violação e a comercialização de dados pessoais. Apenas a título exemplificativo, Pariser (2012, p. 101) descreve a maneira como a Phorm, multinacional britânica recém-chegada ao Brasil, explora os dados dos usuários no ciberespaço. De acordo com o autor, a Phorm tem como objetivo auxiliar os provedores de internet no uso de um recurso chamado Inspeção Profunda de Pacotes de Rede (DPI - Deep Packet Inspection) para obter dados e informações que permitam a análise do tráfego que transita nos servidores desses provedores. Além disso, afirma Pariser, a Phorm objetiva a construção de perfis quase plenos de todos os usuários da Web para a utilização futura na padronização de serviços de publicidade.

É importante destacar que a utilização da DPI foi objeto de deliberação na última conferência da International Telecommunication Union - Telecommunication Standarization Sector (ITU-T), órgão vinculado à Organização das Nações Unidas e responsável pela definição de diretrizes em telecomunicações a ser adotada pelos países membros mediante sua ratificação.

Relevante esclarecer, ainda, que a DPI é um recurso tecnológico com a finalidade de gerenciar o tráfego de rede. Dessa forma, esse recurso possibilita que operadoras de rede realizem a análise profunda, e por isso a denominação "inspeção" é utilizada, dos pacotes de dados que transitam na infraestrutura de rede dessas operadoras, com uma finalidade primária de otimização dos custos, a partir do conhecimento do tráfego demandado pelos usuários. Assim, seria possível identificar quais serviços o usuário demanda maior banda de rede, ou seja, se determinado usuário utiliza a Web para navegação em sites, ou para assistir vídeos, ou acessar redes 
sociais e a utilização da DPI possibilitaria que as operadoras fornecessem um serviço melhor qualificado ao consumidor. (GEERE, 2012)

Por outro lado, conforme afirma Monteiro (2013), do Observatório Brasileiro de Políticas Digitais, a DPI é um recurso tecnológico cujos benefícios são altamente questionáveis por permitir que provedores de acesso à internet obtenham os dados pessoais e monitorem a utilização da rede pelos usuários. Para a pesquisadora, a identificação do tráfego dos usuários poderia provocar "[...] ações desejadas pelo poder público, como controle de conteúdos acessados por cidadãos (censura), ou orientar interesses empresariais, como diferenciação de tráfego para serviços pouco desejados e competitivos aos seus serviços [...] " (MONTEIRO, 2013, p. 1), o que já ocorre em países com regimes governamentais democráticos e não democráticos.

E é justamente nesse aspecto que reside a controvérsia sobre a Recomendação ITU-T Y.2770 (2012) que estabeleceu os requisitos de utilização da DPI nas próximas gerações de redes. Esse documento foi objeto de discussão e deliberação na World Telecommunication Standardization Assembly realizada em Dubai no final de 2012, do qual resultou um tratado que não foi assinado por 55 países-membros, dentre os quais Alemanha, Canadá, Estados Unidos, Chile, Colômbia, Reino Unido e Suécia. (MONTEIRO, 2013)

Apesar de ser signatário do tratado que aprovou a Recomendação referida, o Brasil adota uma postura cautelosa em relação à utilização da DPI pela Phorm em território nacional, conforme se evidencia na Resolução CGI.br/RES/2012/008/P (2012), aprovada na 4a Reunião Ordinária do Comitê Gestor da Internet no Brasil (CGI.br):

Trata-se de se examinar as implicações para a Internet da implantação de uma ferramenta da empresa inglesa Phorm, que tem filiais na Romênia e no Brasil. Essa ferramenta é divulgada no Brasil com o nome de "Sistema Navegador".

Considerando que no "Sistema Navegador", instalado num provedor de acesso à Internet, a publicidade estará sendo feita pela empresa que provê o meio de acesso à Internet, sem deixar alternativas aos usuários que não queiram ser inseridos neste sistema; 
Considerando que o funcionamento do "Sistema Navegador" prevê e depende da cópia ("tap") de todo o tráfego de seus usuários direcionado a servidores HTTP na porta 80/TCP;

Considerando que a descrição do "Sistema Navegador" não é apresentada de forma clara ao consumidor, especialmente quanto à sua funcionalidade e implicações do modelo proposto para publicidade personalizada e, ainda, que o consumidor não tem a seu dispor todas as informações que seriam necessárias para fazer uma escolha adequada que contemple a privacidade e segurança de todos os membros de um domicílio que compartilham o equipamento de acesso;

Considerando que, conforme as descrições técnicas providas acerca do funcionamento do "Sistema Navegador", fica claro que são introduzidas etapas adicionais aos acessos Web, e que não são parte de um acesso regular a uma página Web;

Considerando que um destes passos é o redirecionamento do acesso à primeira imagem referenciada em uma nova seção de navegação para que um "cookie" seja instalado, de forma a dar a opção ao usuário de escolher ou não a ação do "Sistema Navegador" em sua publicidade personalizada, *mas* que, mesmo optando por não usar o "Sistema Navegador" ("opt-out") o usuário continuará tendo seu tráfego redirecionado;

Considerando que este redirecionamento interfere na comunicação adequada e direta entre um "cliente" e um "servidor" na Internet, mesmo nos casos em que o consumidor tenha escolhido a opção de "opt-out";

Considerando que todos estes passos adicionais à navegação possuem o inerente risco de degenerar a qualidade do acesso do consumidor à Internet, além do risco adicional criado pela cópia da navegação que o cliente está fazendo [...]

Nesse caso, o CGI.br entende que o recurso tecnológico utilizado pela Phorm fere tecnicamente alguns dos princípios para a governança e uso da internet no Brasil, que são: o da neutralidade da rede, a partir da filtragem e geração de privilégios de tráfego de acordo com motivos políticos, comerciais, religiosos, culturais e econômicos; e o da padronização e interoperabilidade com o fechamento de padrões e participação da 
operação da internet no país. Ademais, ao manifestar uma postura de não recomendação de uso pelos provedores de acesso à rede no Brasil, o CGI. br tornou claro que o uso do "Sistema Navegador" traz graves ameaças à privacidade dos usuários.

\section{O Tratamento da Privacidade e Proteção dos Dados no Ci- berespaço sob a Perspectiva Brasileira}

No Brasil, assim como em outros diversos Estados, o direito à privacidade é assegurado constitucionalmente como direito humano fundamental. A Constituição Federal brasileira não se restringe apenas ao direito à privacidade, apresentando abrangência em relação à preservação da vida privada e da intimidade da pessoa, a inviolabilidade da correspondência, do domicílio e das comunicações, em consonância com o previsto no artigo $5^{\circ}$, inciso X: "são invioláveis a intimidade, a vida privada, a honra e a imagem das pessoas, assegurado o direito a indenização pelo dano material ou moral decorrente de sua violação" e no inciso XII: "É inviolável o sigilo da correspondência e das comunicações telegráficas, de dados e das comunicações telefônicas, salvo, no último caso, por ordem judicial, nas hipóteses e na forma que a lei estabelecer para fins de investigação criminal ou instrução processual penal". (BRASIL, 1988)

Ora, se há proteção constitucional, por que discutir tal tema? E a Lei a alternativa adequada a resolver problemas jurídicos como o exemplificado anteriormente por Keen e Pariser? Ao encontro da provocação apresentada, e em reflexão à solução de conflitos complexos na órbita jurídica, Streck (2011, p. 46) afirma que o Direito não atende a tais demandas

[...] não porque tal "complexidade" não estaria prevista no sistema jurídico, mas, sim, porque há uma crise de modelo [...] que se instala justamente porque a dogmática jurídica, em plena sociedade transmoderna e repleta de conflitos transindividuais, continua trabalhando com a perspectiva de um direito cunhado para enfrentar conflitos interindividuais, bem nítidos em nossos Códigos [...] 
Diante de tais premissas, pode-se afirmar que as camadas que compõem o sistema de comunicação da internet e do meio digital são cada vez mais controladas. Entretanto, permanecem ainda dúvidas sobre quais são os fatores que se deve considerar efetivos na regulação da internet (LEMOS, 2005, p. 22). Nesse prisma, é relevante considerar o modelo de análise desenvolvido por Lessig (2006), que trata especificamente dos modos de regulação no que tange ao avanço da tecnologia. Para o referido constitucionalista, no início do século XIX, o liberalismo dominante se preocupava com a manutenção e a garantia da liberdade e, diante disso, qualquer ameaça à liberdade provocaria o poder do Estado e sua capacidade de gerar a Lei.

Nesse mesmo sentido, e em relação ao direito brasileiro, para Streck (2011, p. 43) “[...] a dogmática jurídica que o instrumentaliza - está assentado em um paradigma liberal-individualista que sustenta essa desfuncionalidade, que, paradoxalmente, vem a ser a sua própria funcionalidade! [...]". Segundo o autor,

[...] não houve ainda, no plano hermenêutico, a devida filtragem em face da emergência de um novo modo de produção de Direito representado pelo Estado Democrático de Direito - desse (velho/ defasado) Direito, produto de um modo liberal-individualista-normativista de produção de direito. (STRECK, 2011, p. 43)

No contexto da violação ao direito à privacidade e à proteção dos dados pessoais, Lemos (2005, p. 22) indaga sobre quais são os fatores que efetivamente ameaçam a liberdade. De acordo com o autor, no século XIX, a resposta seria a Lei. Todavia, complementa o autor, no contexto da tecnologia dos tempos atuais, a Lei deixou de ser o único fator que contribui a limitação ou flexibilização da liberdade dos indivíduos, ou até mesmo para a regulação da sociedade em rede.

Nesse prisma, Lemos (2005, p. 22) ressalta que o mesmo questionamento sobre quais fatores ameaçam a liberdade individual na sociedade da informação, é possível encontrar no mínimo quatro respostas: a Lei, as normas sociais, o mercado e a arquitetura ou código. Na concepção do autor, entende-se como lei "[...] todo o conjunto normativo estatal, emba- 
sado constitucionalmente, em suas mais diversas naturezas e categorias hierárquicas" (LEMOS, 2005, p. 22). As normas sociais incluem os usos e costumes e "[...]qualquer postulação normativa compartilhada por comunidades ou inerente a determinadas situações e circunstâncias" (LEMOS, 2005 , p. 22). O contexto do mercado "[...] é o outro fator relevante da regulação, por se tratar do mecanismo predominante de acesso aos bens econômicos [...]", somado à arquitetura, que é "[...] a estrutura inerente de como as coisas são construídas e ocorrem”. (LEMOS, 2005, p. 22)

$\mathrm{Na}$ percepção de Lessig (2006, p. 5), na órbita do direito da tecnologia, “[...] o código é a Lei”. O que o professor da Stanford University pretende ao lançar tal assertiva é que as linguagens de programação alcançam muitas vezes relevância superior às estruturas normativas convencionais na órbita da internet e da regulação tecnológica.

Ao analisar as premissas inovadoras apresentadas por Lessig, Lemos $(2005$, p. 22) ressalta que as categorias dogmáticas tradicionais não vislumbram a característica normativa contemporânea proclamada pelo autor, de que o "código é a Lei". Nesse sentido, a partir da ruptura paradigmática na análise do direito por meio da evolução tecnológica, sobretudo no âmbito do ciberespaço, é possível que sejam rediscutidas controvérsias e posicionamentos pretéritos que se julgavam superados e que sejam propostas questões inéditas fundamentadas em aspectos sociológicos, políticos e econômicos, que "[...] de tão interdisciplinares, põem em risco a própria especificidade do direito”. (LEMOS, 2005, p. 8)

Entretanto, para que o Brasil consiga suprir uma série de lacunas normativas que atualmente inviabiliza a atração de investimentos em infraestrutura tecnológica, como é o exemplo da perda de oportunidade da vinda do datacenter da Google, em que o Chile foi vitorioso na disputa (LEMOS, 2013), o "Marco Civil da Internet" representa um avanço em termos de segurança jurídica para o ciberespaço brasileiro.

O Projeto de Lei n. 2.126/2011, que tem por objetivo a instituição do Marco Civil da internet nacional foi construído com uma série de elementos que respeitam os fundamentos que criaram a Web, a partir da consulta colaborativa aos usuários da rede por meio de um blog hospedado no portal Cultura Digital, vinculado ao Ministério da Cultura, bem como 
manifestações via Twitter, utilizando a hashtag “\#marcocivil” como referência ao conteúdo. (BRASIL, 2011)

Ademais, conforme evidenciado na exposição de motivos do referido projeto, a Pesquisa Nacional por Amostra de Domicílios, realizada no ano 2009 pelo Instituto Brasileiro de Geografia e Estatística (IBGE), já sinalizava a existência de 68 milhões de usuários de internet no Brasil, com taxa de crescimento de aproximadamente um milhão a cada três meses. A estatística apresentada representa oportunidades ao país, no entanto, também aponta uma série de riscos, já que nosso país não dispõe de legislação específica para o ciberespaço, no sentido de assegurar os direitos fundamentais e a possibilidade do desenvolvimento econômico e cultural do país. (BRASIL, 2011)

Outrossim, a falta de definição legal específica diante da realidade enfrentada atualmente oportuniza que emanem do Poder Judiciário decisões conflitantes e contraditórias sobre temas que estão diretamente relacionados com o uso da internet (BRASIL, 2011). De acordo com os elementos elencados na exposição de motivos do mencionado projeto de lei, com a ausência de normatização específica, o Brasil convive com diversos riscos, a saber:

a) da aprovação desarticulada de propostas normativas especializadas, que gerem divergência e prejudiquem um tratamento harmônico da matéria;

b) de prejuízos judiciais sensíveis, até que a jurisprudência se adeque às realidades da sociedade da informação;

c) de desencontros ou mesmo omissões nas políticas públicas; e

d) de violação progressiva de direitos dos usuários pelas práticas e contratos livremente firmados. (BRASIL, 2011)

Com isso, a aprovação de uma lei que desenvolva a abordagem da internet tende a viabilizar um melhor diálogo do Direito com as Novas Tecnologias, sobretudo as que envolvem o ciberespaço. Diante de tal necessidade, o CGI.br apresentou em 2009 um documento intitulado "Princípios para a governança e uso da Internet” (BRASIL, 2011), no qual são 
apresentados dez princípios técnicos que asseguram diretrizes básicas para o uso da rede em território nacional.

Todavia, será necessário o amadurecimento normativo brasileiro com a aprovação do Marco Civil da Internet, que trata de forma peculiar os fundamentos, os princípios e os objetivos, bem como a definição de conceitos e de regras de interpretação relacionados ao tema. Além disso, o acesso à internet é reconhecido como um direito essencial ao exercício da cidadania, sendo indispensável o respeito à inviolabilidade e ao sigilo das comunicações e à não suspensão da conexão. O Projeto de Lei do Marco Civil da rede apresenta, ainda, capítulo voltado à tratativa de questões técnicas como o tráfego de dados, a guarda de registros de conexão e acesso a aplicações na rede, a responsabilidade por danos decorrentes de conteúdo gerado por terceiros e a requisição judicial de registros.

\section{Conclusão}

Há pouco mais de uma década, quando a internet ainda ensaiava os primeiros passos em território brasileiro, o compositor brasileiro e defensor da liberdade dos direitos no ciberespaço, Gil (ROHTER, 2011) profetizou na música "On the internet" uma das primeiras impressões do que a rede representava na vida dos usuários: "I want to get on the Web, Promote a debate, Bring together on the internet, A group of fans from Connecticut, I want to go on the Web to contact, Homes in Nepal and bars in Gabon".

Definitivamente vive-se num tempo em que a simultaneidade proporcionada pela internet oportuniza a vivência de uma experiência revolucionária da comunicação, do relacionamento social e do consumo. No sentido apresentado por Gil, vive-se na era dos websites e a transcendência dos gigabytes nas "nuvens" com a cloud computing. Diante disso, é inegável que as relações estabelecidas no ambiente virtual carecem de análise da ciência jurídica sob os prismas sociológico, hermenêutico, jurisdicional e do modus operandi que a tecnologia instiga a investigar.

O consumidor moderno cada vez mais procura a internet para realizar transações comerciais, e isso ocorre por diversos fatores, como por 
exemplo, a otimização do tempo disponível, a tentativa de manutenção da privacidade e a amplitude na realização de pesquisas de preços.

Figura-se uma geração de indivíduos cada vez mais familiarizados com o ato de "googlear". Sim, "googlear", da tradução do verbo "to google", inserido no vocabulário do inglês estadunidense após a transformação do buscador Google em uma das maiores potências em comunicação e informação do Planeta. A internet e, sobretudo, o ato de "Googlear", trouxeram repercussões das mais diversas na vida individual e em sociedade, colocando em xeque diversos paradigmas da vida pós-moderna: o consumo, as relações sociais, a comunicação e a informação jamais serão as mesmas.

O ciberespaço, de um modo geral, oferece novas e diferentes perspectivas e expectativas do futuro. Há um tempo, quando se assistia a um filme de ficção científica, imaginava-se o futuro que estava por vir. Agora, tem-se a impressão de que se aproxima da certeza de que o futuro é agora, e nesse futuro presente, indubitavelmente, é necessário promover uma imersão conceitual do Direito no ciberespaço, visando preservar os direitos humanos fundamentais à privacidade e à proteção de dados pessoais.

\section{Referências}

\section{BARBER, Lionel. How a soccer star sparked the freedom} debate of our age. Financial Times. [2013]. Disponível em: $<$ http:// www.ft.com/cms/s/0/45b97284-8895-11e0-afe1-00144feabdc0. html\#axzz2V6M1phDE>. Acesso em: 15 jan. 2013.

BRASIL. Comitê Gestor da Internet no Brasil. Resolução CGI. br/RES/2012/008/P. [2012]. Disponível em: <http://www.cgi.br/ regulamentacao/pdf/resolucao-2012-008.pdf>. Acesso em: 23 jul. 2012.

BRASIL. Comitê Gestor da Internet no Brasil. Resolução n. CGI. br/RES/2009/003/P. [2009]. Disponível em: <http://www.cgi.br/ regulamentacao/pdf/resolucao-2009-003-pt-en-es.pdf $>$. Acesso em: 14 jan. 2013. 
BRASIL. Constituição Federal da República Federativa do Brasil. 1988. Disponível em: <http://www.planalto.gov.br/ccivil_03/constituicao/ constituicao.htm>. Acesso em: 23 dez. 2012.

BRASIL. Exposição de motivos ao Projeto de Lei n. 2.126/2011. Disponível em: $<$ http://www.planalto.gov.br/ccivil_03/Projetos/ ExpMotiv/EMI/2011/86-MJ\%20MP\%20MCT\%20MC.htm>. Acesso em: 24 dez. 2012.

CASTELLS, Manuel. A sociedade em rede: a era da informação: economia, sociedade e cultura. São Paulo: Paz e Terra, 2002. v. 1.

GEERE, Duncan. How Deep Inspection Works? Wired Magazine, April 27 $7^{\text {th }}$ 2012. Disponível em: <http://www.wired.co.uk/news/ archive/2012-04/27/how-deep-packet-inspection-works $>$. Acesso em: 3 maio 2012.

\section{INTERNATIONAL TELECOMMUNICATIONS UNION.}

Recomendation Y. 2770. [2013]. Disponível em: <http://www.itu.int/ rec/T-REC-Y.2770-201211-I/en>. Acesso em: 4 abr. 2013.

KEEN, Andrew. O culto do amador: como blogs, MySpace, YouTube e a pirataria digital estão destruindo nossa economia, cultura e valores. Tradução: Maria Luiza X. de A. Borges. Rio de Janeiro: Zahar, 2009.

. Vertigem digital: por que as redes sociais estão nos dividindo, diminuindo e desorientando. Tradução: Alexandre Martins. Rio de Janeiro: Zahar, 2012.

LEMOS, Ronaldo. Brasil vive momento de "apagão" para leis de internet. Folha de São Paulo, São Paulo, 18 de março de 2013. Disponível em: <http://www1.folha.uol.com.br/colunas/ ronaldolemos/1247892-brasil-vive-momento-de-apagao-para-leis-deinternet.shtml>. Acesso em 20 mar. 2013.

. Direito, tecnologia e cultura. E-book publicado pela licença Creative Commons na plataforma Google Books. [2005. p. 22]. Disponível em: <http://books.google.com/books?hl=en\&lr=\&id=xG2W7YnTfUC\&oi=fnd\&pg=PA7\&dq=DIREITO,+TECNOLOGIA + E + CULTURA\& \&ots $=$ PXCUp6AS7u\&sig=2dkpHEIZXv_3UBOaPkho2wM KO58>. Acesso em: 15 jan. 2013. 
LESSIG, Lawrence. Code v2. New York: Basic Books, 2006. MONTEIRO, Marília. O Padrão técnico de inspeção profunda de pacotes de rede. Observatório Brasileiro de Políticas Digitais. Rio de Janeiro: FGV, 2013. Disponível em: < http://observatoriodainternet.br/opadrao-tecnico-de-inspecao-profunda-de-pacotes-de-rede $>$. Acesso em: 12 fev. 2013.

ORWELL, George. 1984: Planet eBooks. [2013]. Disponível em: $<$ http:// www.planetebook.com/1984.asp>. Acesso em: 13 fev. 2013.

PARISER, Eli. O filtro invisível: o que a internet está escondendo de você. Rio de Janeiro: Zahar, 2012. p. 101.

ROHTER, Larry. Gilberto Gil hears the future, some rights reserved. The New York Times, USA, 11 de março de 2007. Disponível em: <http:/www.nytimes.com/2007/03/11/arts/music/11 roht. html?pagewanted=all\&_r=0>. Acesso em: 29 ago. 2011.

STRECK, Lenio Luiz. Hermenêutica jurídica e(m) crise: uma exploração hermenêutica da construção do Direito. 10. ed. Porto Alegre: Livraria do Advogado, 2011.

VASCONCELOS, Fernando Antonio de. Internet: a responsabilidade do provedor pelos danos praticados. Curitiba: Juruá, 2003. 
Salete Oro Boff é Doutora em Direito pela UNISINOS/RS, em 2005, PósDoutorado na UFSC/SC, em 2008, Professora do Programa de Pós-Graduação, Mestrado e Doutorado em Direito da UNISC/RS, Linha de Pesquisa "Políticas Públicas de inclusão social". Professora e pesquisadora do Programa de PósGraduação em Mestrado em Direito da IMED - Faculdade Meridional/RS, linha de pesquisa "Fundamentos Normativos da Democracia Sustentável" e do IESA. E-mail: salete.oro.boff@terra.com.br.

Endereço profissional: Rua Uruguai, n. 1071/802, Centro, Passo Fundo, RS, CEP 99.010-110.

Vinícius Borges Fortes é Mestre em Direito pela UCS/RS, em 2011, doutorando em Direito pela UNESA/RJ, linha de pesquisa Direitos fundamentais e novos direitos". Professor universitário na Faculdade Meridional (IMED), pesquisadormembro do Grupo de Pesquisa "Novas Tecnologias, marcos regulatórios e reconhecimento de direitos na diversidade cultural", certificado pela IMED. E-mail: vinicius@borgesfortes.com.br.

Endereço profissional: Rua Uruguai, n. 1071/802, Centro, Passo Fundo, RS, CEP 99.010-110. 